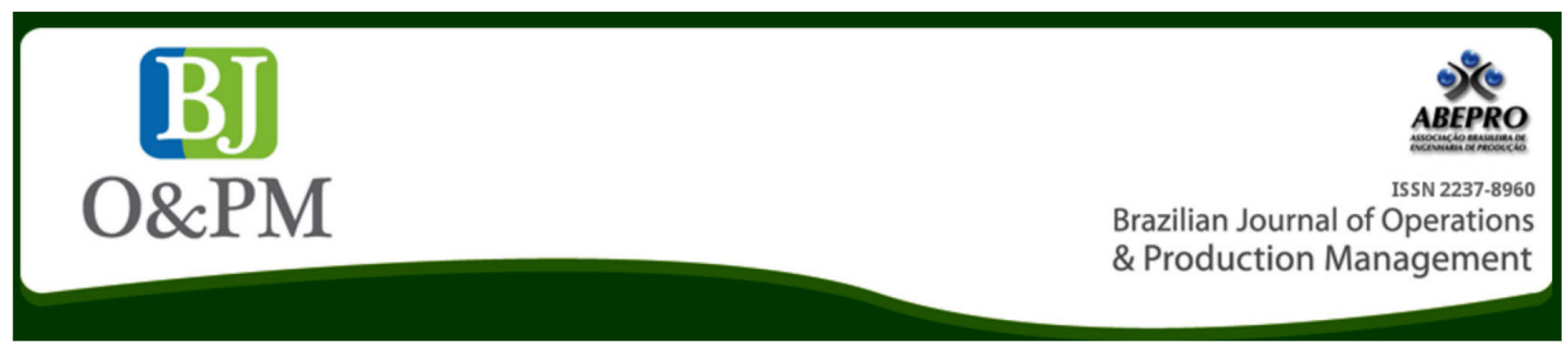

\title{
MULTI-CRITERIA SUPPLIER SELECTION USING FUZZY ANALYTIC HIERARCHY PROCESS: CASE STUDY FROM A BRAZILIAN RAILWAY OPERATOR
}

\author{
Rodrigo Barbosa de Santis ${ }^{1}$, Leonardo Golliat ${ }^{1}$, Eduardo Pestana de Aguiar ${ }^{2,3}$ \\ 1 Graduate Program in Computational Modeling, Federal University of Juiz de Fora; \\ 2 Department of Mechanic and Industrial Engineering, Federal University of Juiz de Fora; \\ 3 Electrical Engineering Post-Graduation Program, Federal University of Juiz de Fora
}

\begin{abstract}
The supplier selection problem has been discussed in literature within the supply chain management subject and it is extremely important due to its impact on the entire supply chain configuration, strategy and performance. This work presents a decision model based on the fuzzy analytic hierarchy process method and its application in a real case of maintenance supplier selection in a large Brazilian railway operator. Eight criteria were adopted - technical capacity, financial status, relationship, operations management, security management, infrastructure, historic performance and costs - for evaluating five potential suppliers. In the case study, both first and second ranked suppliers by the method have been selected by the company for providing the services and the model was adopted as a standard procedure within the organization for contracts over US\$300,000.
\end{abstract}

Keywords: supplier selection; railway maintenance; multi-criteria decision making; analytic hierarchy process; fuzzy logic. 


\section{INTRODUCTION}

The supplier selection is defined as the process of review, selection and evaluation of companies composing a supply chain. It is considered to be one of the most important processes of the purchasing function, due to its direct impact within the configuration and operational performance of a supply chain.

Several factors have been turning the purchasing decision more complicate: the globalization of commerce and the internet, which increases the choice possibilities for buyers; the changes in the customers preference, demanding broader and faster supplier selection processes; the public procurement regulations demanding more transparency in decision-making; and new organizational formats, which lead to the involvement of more decision agents within the selection processes (De Boer et al., 2001).

In modern supply chain management, companies seek to keep long term partnerships with a reduced number of reliable suppliers and their selection depends more and more on other quantitative and qualitative features, beyond the cost of acquisition (Chai et al., 2013). In this context, the development of systematic and transparent decision models is necessary for aiding the process of selecting suppliers.

Multi-criteria decision-making (MCDM) methods play an important role in this specific problem, given its effectiveness on evaluating several alternatives submitted to multiple criteria - also known as attributes or objectives - under an environment of uncertainty. These criteria are defined according to the specific objectives of each company and must be applied in a clear and concise way in the selection process, in order to promote synergy among all components of a supply chain.

To effectively handle the complexity of this problem, researches have been applying integrated approaches of MCDM along with others from different disciplines of knowledge, such as mathematical programming and artificial intelligence (Ho et al., 2010; Chai et al., 2013; Lima Junior et al., 2013). Although the hybrid models integrating MCDM fuzzy logic hybridization has become one of the most popular methods for addressing the supplier selection problem in all sorts of industries (Chai et al., 2013), no specific model has been proposed so far for the railway industry.

This paper proposes the application of a decision model based on the fuzzy analytic hierarchy process (fuzzy AHP) method, adapted for maintenance supplier contracting within the railway industry.

The major contributions of this paper are stated as follows:
1) applying a multi-criteria decision making model in a real-life case study of supplier selection for maintenance service within MRS Logistica, a large Brazilian railway operator;

2) defining and understanding the specific criteria applied in the railway sector, based on the preferences of experienced executives, who may be used as reference for other researchers;

3) evaluating the different outcomes of fuzzy AHP and analytic hierarchy process (AHP) methods through the adoption of a conversion of linguistic scale between both methods.

The major conclusions are as follows:

1) The results from the method were the same adopted by the company in the selection: both $1^{\text {st }}$ and $2^{\text {nd }}$ placed suppliers have been hired for service providing;

2) The most valued criteria in the process were "security management" and "cost", both known as relevant attributes in the transportation sector;

3) Different ranking orders resulted from fuzzy AHP and AHP methods $-3^{\text {rd }}$ and $5^{\text {th }}$ ranked suppliers swapped places - and a considerable difference was obtained in alternative priority weights.

This paper is organized in five sections. Following this Introduction, in Section 2, it is provided an analysis of recent published articles concerning the supplier selection problem in the railway sector along with the most common methods applied. In Section 3, a background of AHP, triangular fuzzy numbers and the extended analysis calculation steps are presented. Next, in Section 4, we describe the application of fuzzy AHP approach in a real-world hiring situation. Finally, Section 5 concludes this paper with some recommendations for model developments in the future.

\section{LITERATURE REVIEW}

The supply chain management shows an important competitive advantage for companies that successfully apply its concepts. One example is the case study of British Rail that, along the decades of 1980's and 1990's, changed the traditional approach of strictly competitive procurement by the development of a reduced number of suppliers, applying standards and establishing minimum performance targets to be achieved by its partners, simulating continuous improvement, quality, and innovation throughout the chain (Boyett et al., 1996). 
Despite this fact, there are few case studies about MCDM models applications in the supplier selection process within the railway sector. Dulmin et Mininno (2003) first proposed the application of a model based on PROMETHEE and GAIA methods for supplier selection in a mid-sized Italian company on rail and road transport sector. More recently, Bruno et al. (2012) presented a case study of application of the AHP method in a specific component of the traction system in a leading manufacturing company of railway equipment in Italy.

Surveys pointed out that AHP and fuzzy AHP methods, proposed by Saaty (1987) and Chang (1996), respectively, had been the most popular techniques to address the supplier selection problem so far (Ho et al., 2010; Chai et al., 2013; Lima Junior et al., 2013). Several case studies have been published. Kahraman et al. (2003) applied the Fuzzy AHP to determine the most suitable suppliers for providing services for a white goods manufacturer; Chan et Kumar (2007) developed a model for global supplier development, considering risk factors; Cebeci (2009) proposed a fuzzy AHP model using balanced scorecard (BSC) to select a suitable enterprise resource planning (ERP) systems for the textile industry; Chamodrakas et al. (2010) incorporate a fuzzy AHP approach for supplier selection in electronic marketplaces; Killinci et Onal (2011) applied the method in a large white good manufacturer to select a supplier of one critical component in the production of washing machine units; Catak et al. (2012) applied the method for selecting the best database management system for the Turkish national identity card management project; Ayhan (2013) applied a fuzzy AHP based model in a gear motor company; and Yadav et Sharma (2015) propose a model for the automobile industry based on fuzzy AHP approach.

Table 1 presents a summary of case studies of MCDM methods application within several industries found in literature so far. Based on this review, it is argued that the most common criteria applied in supplier selection models are cost, quality, relationship, financial status, and management systems, depending specifically on the nature of the sector, company and/or procurement process. Additionally, Villanueva-Ponce et al. (2015) identify the growth of a new set of green criteria adopted in supply chain management, such as environmental competencies, green product design, carbon emission management, energy consumption, green material coding, management of hazardous substances, waste management and recycling, among others.

Some authors propose the application of a type-2 fuzzy sets application along with AHP (Wang et al., 2012; Uçal Sarý et al., 2013; Cevik Onar et al. 2014; Abdullah et Najib, 2014), while Memon et al. (2015) suggest using the grey system theory and uncertainty theory with the method, for handling fuzziness. Yet, those approaches still need evaluation for understanding whether the inherent computational complexity increase really pays off.

\section{AHP AND FUZZY AHP}

The AHP is a nonlinear framework for carrying out both deductive and inductive thinking by taking various factors into consideration to arrive at a conclusion or synthesis. AHP allows decomposing a main problem in several performance assessment levels, which considers objective or subjective attributes, concurrent or not among them. Thus, it becomes clearer for the decision-makers which is the problem and how to come to a solution. The basic steps for performing the AHP method are: 1) to decompose the problem into independent levels and sublevels, from the more general or uncertain to the more specific and concrete; 2) to construct the decision matrix from pair-wise comparison judgments and 3) to synthesize weights in all inferior levels until reaching a global priority index (Saaty, 1987).

Table 1. Methods and criteria applied by authors for assessing supplier selection in transportation and other sectors.

\begin{tabular}{|c|c|c|c|}
\hline Sector & Method & Criteria & Author \\
\hline $\begin{array}{l}\text { Rail and road } \\
\text { transportation }\end{array}$ & PROMETHEE + GAIA & Technical aspects of new product development sourcing & $\begin{array}{l}\text { Dulmin et Mininno } \\
\text { (2003) }\end{array}$ \\
\hline White goods & Fuzzy AHP & Financial, management, quality, product, and service & Kahraman et al. (2003) \\
\hline Manufacturing & Fuzzy AHP & Cost, quality, service, supplier, and risk & Chan et Kumar (2007) \\
\hline Textile & Fuzzy AHP + BSC & Technical aspects of enterprise management systems & Cebeci (2009) \\
\hline E-commerce & $\begin{array}{l}\text { Fuzzy AHP + Fuzzy pro- } \\
\text { gramming }\end{array}$ & Quality, cost and delivery & $\begin{array}{l}\text { Chamodrakas et al. } \\
\text { (2010) }\end{array}$ \\
\hline White goods & Fuzzy AHP & $\begin{array}{l}\text { Financial status, management, technical, quality, location, } \\
\text { capacity, price, support and delivery }\end{array}$ & Killinci et Onal (2011) \\
\hline $\begin{array}{l}\text { Rail transpor- } \\
\text { tation }\end{array}$ & AHP & $\begin{array}{l}\text { Process and product quality, service level, management and } \\
\text { innovation, and financial position }\end{array}$ & Bruno et al. (2012) \\
\hline Government & Fuzzy AHP & Technical aspects of database managements systems & Catak et al. (2012) \\
\hline Motors & Fuzzy AHP & Quality, origin, cost, delivery, after sales & Ayhan (2013) \\
\hline Automobile & Fuzzy AHP & Quality, cost, delivery, service, relationship and flexibility & Yadav et Sharma (2015) \\
\hline
\end{tabular}


The alternative comparisons are performed two by two by decision-makers, from a natural scale from 1 to 9 . The Fuzzy AHP method replaces the traditional scale for a triangular fuzzy number scale. Therefore, it can effectively handle the fuzziness in the linguistic judgments of the decision-makers, receiving better acceptance by researchers than the original crisp method.

\subsection{Triangular fuzzy numbers}

A fuzzy set is a class of objects without a precisely defined criterion of membership, expressed by a function that assigns a grade of membership ranging between 0 and 1 to each object (Zadeh, 1965). The theory plays an important role in mathematical and programming applications that have to deal with some degree of uncertainty.

A triangular fuzzy number (TFN) $\mathrm{M}$ is shown in Fig. 1. A TFN can be simply denoted as a triplet $(I, m, u)$, where $I, m$, and $u$ indicate the lower, middle and upper values that describe a fuzzy event, and $I \leq \mathrm{m} \leq \mathrm{u}$.

The membership function can be defined as:

$$
\mu_{M}(x)=\left\{\begin{array}{lc}
\frac{x-l}{m-l}, & x \in[l, m], \\
\frac{x-u}{m-u}, & x \in[m, u], \\
0, & \text { otherwise. }
\end{array}\right.
$$

When $\mathrm{l}=\mathrm{m}=\mathrm{u}$, it is a non-fuzzy number by convention (Chang, 1996; Chan et Kumar, 2007). The higher the value of (u-I) or $(I-u)$, the greater is the fuzziness of the judgment. Fuzzy numbers are intuitively easy to use in expressing the decision-maker's qualitative assessments. A fuzzy number can be given by its corresponding left and right representation of each degree of membership (Kahraman et al., 2004; Chan et Kumar, 2007; Killinci et Onal, 2011)

$$
M=M^{l(y)}, M^{r(y)}=(l+(m-l) y, y+(m-u) y), y \in[0,1]
$$

where $I(y)$ and $r(y)$ denote the left side representation and the right side representation of a fuzzy number, respectively. The algebraic operations with fuzzy numbers can be found in Chang (1996) and Kahraman et al. $(2003,2004)$.

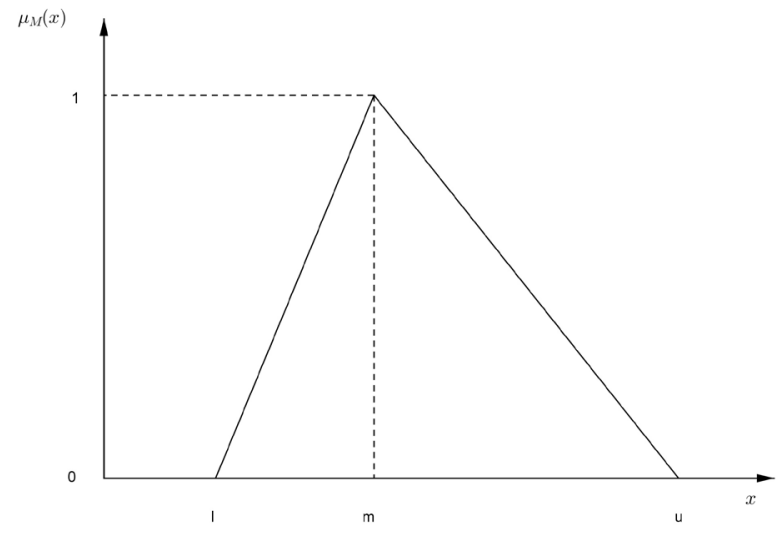

Figure 1. A triangular fuzzy number . Source: Kahraman et al. (2005)

\subsection{Extended analysis method on fuzzy AHP}

Let the object set $\mathrm{X}=\left\{x_{1}, x_{2}, \ldots, x_{n}\right\}$ and the goal set $\mathrm{U}=\left\{u_{1}\right.$, $\left.u_{2}, \ldots, u_{m}\right\}$, the $\mathrm{m}$ extent analysis values (Chang, 1996) for each object are obtained by the following signs:

$$
M_{g_{i}}^{1}, M_{g_{i}}^{2}, \ldots, M_{g_{i}}^{m}, i=1,2, \ldots, n
$$

where all $M_{g}^{j}(j=1,2, \ldots, m)$ are triangular fuzzy numbers.

The value of fuzzy synthetic with respect to th object is defined by (Kahraman et al., 2004; Killinci et Onal, 2011)

$$
S_{i}=\sum_{j=1}^{m} M_{g_{i}}^{j} \odot\left[\sum_{i=1}^{n} \sum_{j=1}^{m} M_{g_{i}}^{j}\right]^{-1} .
$$

To obtain $\sum_{j=1}^{m} M_{g_{i}}^{j}$, the fuzzy addition operation of $\mathrm{m}$ extent analysis values is performed for a particular matrix, such that

$$
\sum_{j=1}^{m} M_{g_{i}}^{j}=\left(\sum_{j=1}^{m} l_{j}, \sum_{j=1}^{m} m_{j}, \sum_{j=1}^{m} u_{j}\right)
$$

and to obtain $\left[\sum_{i=1}^{n} \sum_{j=1}^{m} M_{g_{i}}^{j}\right]^{-1}$, it is performed the fuzzy addition operation of $M_{g}^{j}(j=1,2, \ldots, m)$ values such that

$$
\sum_{i=1}^{n} \sum_{j=1}^{m} M_{g_{i}}^{j}=\left(\sum_{i=1}^{n} l_{i}, \sum_{i=1}^{n} m_{i}, \sum_{i=1}^{n} u_{i}\right)
$$

then the inverse of the vector in eq. is computed (6), such that 


$$
\left[\sum_{i=1}^{n} \sum_{j=1}^{m} M_{g i}^{j}\right]^{-1}=\left(\frac{1}{\sum_{i=1}^{n} u_{i}} \frac{1}{\sum_{i=1}^{n} m_{i}} \frac{1}{\sum_{i=1}^{n} l_{i}}\right) .
$$

The degree of possibility $M_{2} \geq M_{1}$ is defined as

$$
V\left(M_{2} \geq M_{1}\right)=\sup _{y \geq x}\left[\min \left(\mu_{M_{1}}(x), \mu_{M_{2}}(y)\right)\right]
$$

and can be equivalently expressed as follows:

$$
\begin{aligned}
& V\left(M_{2} \geq M_{1}\right)=\operatorname{hgt}\left(M_{1} \cap M_{2}\right)=\mu_{M_{2}}(d) \\
= & \left\{\begin{array}{cc}
1, & \text { if } m_{2} \geq m_{1}, \\
0, & \text { if } l_{1} \geq u_{2}, \\
0, & \text { otherwise. }
\end{array}\right.
\end{aligned}
$$

where is the ordinate of the highest intersection point between $\mu_{M_{1}}$ and $\mu_{M_{2}}$. In Fig. 2, the intersection between $M_{1}$ and $M_{2}$ can be seen.

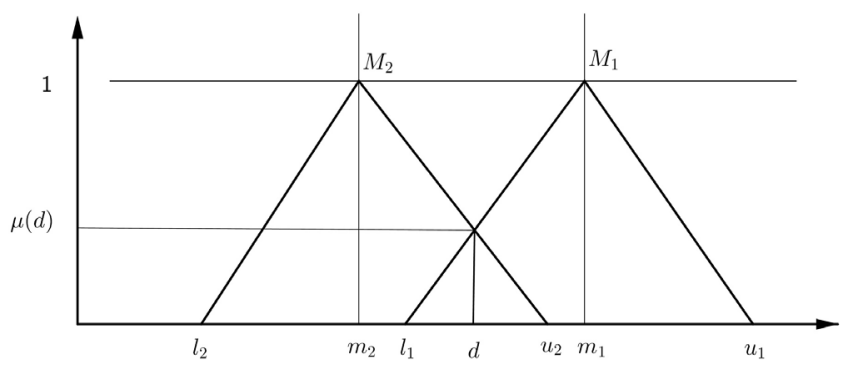

Figure 2. The intersection between $\mathrm{M} 1$ and $\mathrm{M} 2$. Source: Kahramah et al. (2005)

To compare $M_{1}$ and $M_{2}$, we need both the values of $V\left(M_{1} \geq M_{2}\right)$ and $V\left(M_{2} \geq M_{1}\right)$.

The degree of possibility for a convex fuzzy number to be greater than the $k$ convex fuzzy numbers $M_{i}(i=1,2, \ldots, k)$ can be defined by

$$
\begin{aligned}
& V\left(M \geq M_{1}, M_{2}, \ldots, M_{k}\right) \\
& =V\left(M \geq M_{1}\right) \text { and }\left(M \geq M_{2}\right) \text { and } \ldots \text { and }\left(M \geq M_{k}\right)=\min V\left(M \geq M_{i}\right), i=1,2,3, \ldots, k
\end{aligned}
$$

Assuming that

$$
d^{\prime}\left(A_{i}\right)=\min V\left(S_{i} \geq S_{k}\right) .
$$

for $k=1,2, \ldots, n ; k \neq i$. Then the weight vector is given by eq. (13), after normalization.

$$
W=\left(d\left(A_{1}\right), d\left(A_{2}\right), \ldots, d\left(A_{n}\right)\right)^{T}
$$

where $W$ is a non-fuzzy number that represents the weights of each alternative compared to another.

\section{CASE STUDY: APPLICATION IN SUPPLIER SELECTION WITHIN THE RAILWAY SECTOR}

A large Brazilian freight railway operator company, MRS Logistica (http://www.mrs.com.br), recurrently selects suppliers for maintenance services contracts. The company is responsible for operating a 1,654 kilometers rail network presented in a region that concentrates half of the country's gross domestic product. One third of all rail cargo of the country is transported by its trains, including containers, steel, cement, bauxite, agricultural products, petroleum coke, coal and iron ore, which represents $20 \%$ of all exports.

In this particular study, the company intends to select a new supplier for providing maintenance services in all of its permanent ways, a representative contract that may represent a critical impact on its whole operation. There are several companies offering the service. A group of two specialists are responsible for assessing the suppliers, through evaluation visits, and technical and commercial proposals.

\subsection{Problem modeling}

Several evaluation documentation previously applied in the supplier selection processes by the company were analyzed along with the literature attributes adopted by other authors for addressing the supplier selection problem. The research pointed to a reduced list of 36 sub-attributes grouped in 8 main attributes. The proposed list was then validated by the specialists involved in the procurement process. The defined criteria are detailed as follows:

1) Technical capacity (TEC) - It evaluates the capacity of the firm fulfilling technical requirements for the service and provides specific solutions. Certificates from acknowledged institutions, research \& development capabilities and historic data have been used for evaluating this attribute.

2) Financial status (FIN) - Financial health is recognized as a relevant criterion for supply risk assessment. Several financial measures are taken into account as liquidity and investment return rate. Asset turnover and degree of dependency on the contract are evaluated in these criteria.

3) Relationship (REL) - Commercial relations can present a differential advantage when selecting a supplier. Payment conditions, on time delivery records, 
volume and reprogramming flexibility and anomalies treatment are evaluated in this item.

4) Operations management (OPE) - Operations management level is believed to contribute to better quality and productivity along a supply chain. Under this perspective, quality systems, material and process control, maintenance and calibration, planning and staff training and other features are assessed.

5) Security management (SEC) - Security is one of the most important criterion for transportation companies, as any failure can lead to accidents with huge social, environmental and financial impacts. Compliance with safety standards, security device appliances in machines, personal and group protection equipment usage, security and environmental management certificates are checked in this criterion.

6) Infrastructure (INF) - A proper infrastructure and resources are necessary for providing the service. Adequate conservation of assets (vehicles and equipment), work stations and physical location are checked by the specialists.

7) Historic performance (HIS) - Previous experiences in providing the service in the past can influence the performance of the firm in the future. In this attribute, references of other companies, legal pendencies and security and hazard records are checked.

8) Costs (COS) - This attribute considers the total cost estimated for each alternative, considering budget restrictions and consistency analysis.

The numbers of potential suppliers technically qualified by the company for providing the service was equal to 5 . Fig. 3 shows the general hierarchy structure constructed for the specific problem, composed by three different levels: the goal (selection of the best supplier), the attributes (criteria) and the alternatives (suppliers).

\subsection{Attributes and alternatives weight calculation}

Printed questionnaires were applied in order to collect the pair-wise comparison judgments, reached by consensus with respect to each criteria and alternatives, from the perceptions and previous experiences of the executives involved in the process.

Firstly, the main attributes were compared with respect to the main goal, and then each supplier was compared with respect to each attribute. Linguistic variables were applied to represent each comparison, according to the corresponding triangular fuzzy number, shown in Table 2.

Table 2. Linguistic variables and their corresponding fuzzy numbers.

\begin{tabular}{ccc}
\hline $\begin{array}{c}\text { Fundamental } \\
\text { scale }\end{array}$ & Definition & $\begin{array}{c}\text { Fuzzy triangu- } \\
\text { lar scale }\end{array}$ \\
\hline 1 & Equally preferred & $(1,1,1)$ \\
3 & Weakly preferred & $(1,3 / 2,2)$ \\
5 & Fairly strongly preferred & $(3 / 2,2,5 / 2)$ \\
7 & Very strongly preferred & $(2,5 / 2,3)$ \\
9 & Absolutely preferred & $(5 / 2,3,7 / 2)$ \\
\hline \multicolumn{3}{c}{}
\end{tabular}

The superior part of the triangular decision matrix was constructed with the corresponding fuzzy numbers of each linguistic judgment collected in the questionnaires. Table 3 shows the superior part of fuzzy evaluation matrix with respect to the goal. Table 4 and Table 5 show the superior part of fuzzy evaluation matrix with respect to the attribute "security management" and "cost", respectively. The other matrices have been omitted due to the limited space of this paper. The inferior part of the matrix is then completed with the reciprocity of each fuzzy number $(l, m, u)$, given by $M^{-1}=(1 / u, 1 / m, 1 / l)$.

The consistency ratios of each formed matrix were checked by the AHP method after converting the comparison matrix to a crisp number using the function

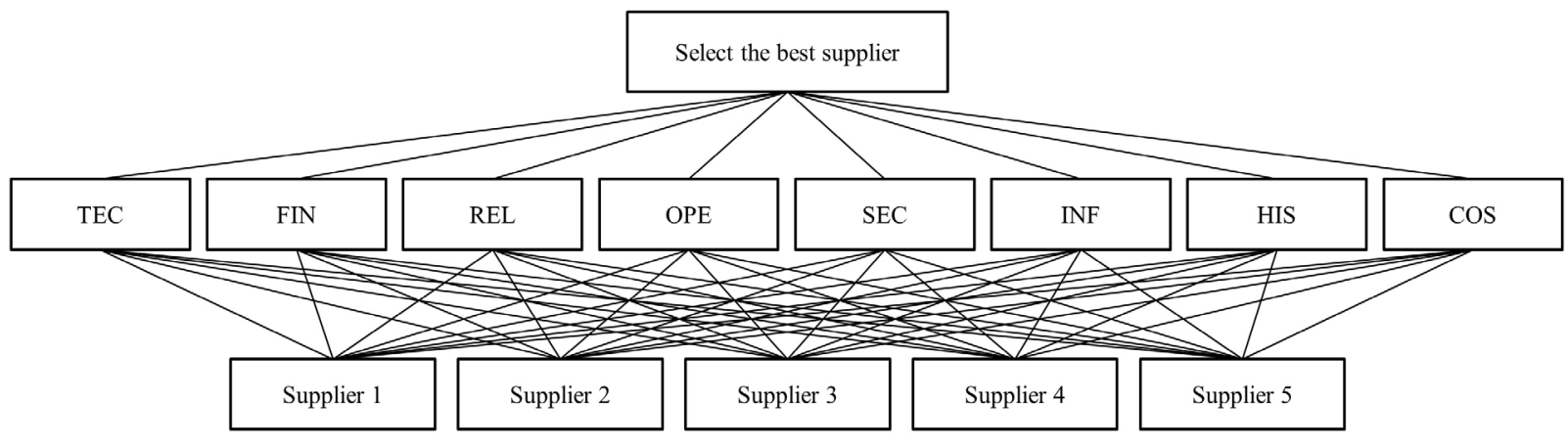

Figure 3. The hierarchy structure of the problem. Source: Elaborated by the authors.

Source: The authors own. 
Table 3. Evaluation matrix with respect to the criterion "Select best supplier".

\begin{tabular}{|c|c|c|c|c|c|c|c|c|}
\hline & TEC & FIN & REL & OPE & SEC & INF & HIS & COS \\
\hline TEC & $(1,1,1)$ & $\left(\frac{5}{2}, 3, \frac{7}{2}\right)$ & $(1,1,1)$ & $\left(\frac{5}{2}, 3, \frac{7}{2}\right)$ & $\left(\frac{2}{7}, \frac{1}{3}, \frac{2}{5}\right)$ & $(1,1,1)$ & $(1,1,1)$ & $\left(\frac{2}{7}, \frac{1}{3}, \frac{2}{5}\right)$ \\
\hline FIN & $(1,1,1)$ & $\left(\frac{2}{5}, \frac{1}{2}, \frac{2}{3}\right)$ & $\left(\frac{2}{7}, \frac{1}{3}, \frac{2}{5}\right)$ & $\left(\frac{2}{9}, \frac{1}{4}, \frac{2}{7}\right)$ & $\left(\frac{2}{7}, \frac{1}{3}, \frac{2}{5}\right)$ & $\left(\frac{2}{7}, \frac{1}{3}, \frac{2}{5}\right)$ & $\left(\frac{2}{7}, \frac{1}{3}, \frac{2}{5}\right)$ \\
\hline REL & & $(1,1,1)$ & $(1,1,1)$ & $\left(\frac{2}{7}, \frac{1}{3}, \frac{2}{5}\right)$ & $(1,1,1)$ & $(1,1,1)$ & $\left(\frac{2}{7}, \frac{1}{3}, \frac{2}{5}\right)$ \\
\hline OPE & & & & $(1,1,1)$ & $\left(\frac{2}{7}, \frac{1}{3}, \frac{2}{5}\right)$ & $(1,1,1)$ & $(1,1,1)$ & $\left(\frac{2}{7}, \frac{1}{3}, \frac{2}{5}\right)$ \\
\hline SEC & & & & & $(1,1,1)$ & $\left(\frac{5}{2}, 3, \frac{7}{2}\right)$ & $\left(\frac{5}{2}, 3, \frac{7}{2}\right)$ & $\left(\frac{5}{2}, \frac{3}{2}, \frac{7}{2}\right)$ \\
\hline INF & & & & & & $(1,1,1)$ & $(1,1,1)$ & $\left(\frac{2}{7}, \frac{1}{3}, \frac{2}{5}\right)$ \\
\hline HIS & & & & & & & $(1,1,1)$ & $\left(\frac{2}{7}, \frac{1}{3}, \frac{2}{5}\right)$ \\
\hline COS & & & & & & & & $(1,1,1)$ \\
\hline
\end{tabular}

Source: The authors own.

$M_{\text {crisp }}=(4 \otimes m+l+u) / 6$ (Kwong et Bai, 2003; Killinci et Onal, 2011). The consistency ratio of each comparison matrix found was under 0.10 , thus validating the judgments performed by the group.

From the fuzzy evaluation matrix in Table 3, the fuzzy synthetic extent values were calculated through eq. (4). The degree of possibility of over is given by eq. (9), (10). The minimum degree of possibility is calculated by eq. (12), which composes each element of the unbalanced vector $W^{\prime}$. Finally, the normalized vector $W$ is given by eq. (14).

The same calculations were applied to the other pair-wise comparison matrixes and the priority weights of each alternative were also calculated, and are shown in Table 6. All operations were performed using the software GNU Octave (2016).

\section{RESULTS AND DISCUSSION}

The priority weights of the attributes and alternatives were aggregated into the final priority weights of each alternative supplier. In Table 6, the first row shows the weight calculated for each attribute, and each sub-column represents the weight evaluation of suppliers for each attribute. The last column on the right shows the final priority of each alternative.
An alternative with a higher score over another represents a preferred supplier. Thus, the preference order of the alternatives is Supplier $4 \geq$ Supplier $1 \geq$ Supplier $3 \geq$ Supplier $2 \geq$ Supplier 5 . The only attributes that were considered by the fuzzy AHP method as influencing the particular selection were security management and costs, which may reflect the major performance objectives of this particular supply chain. It must be pointed out, however, that, for different selection problems in the same company, other attributes may drag more attention.

The same data collected were applied using the classic AHP method, considering the corresponding crisp number in fundamental scale, and the results are shown in Table 7. The preference of the alternatives has changed to Supplier 4 $\geq$ Supplier $1 \geq$ Supplier $5 \geq$ Supplier $2 \geq$ Supplier 3 .

The different results from both methods can be explained by the non-valued weights returns in the fuzzy AHP. Some criteria in which Supplier 5 has presented a superior performance, such as "technical capacity", "financial status" and "relationship" were not taken in account in account for the final priority weight of the alternative, since the weights for these criteria were 0.00 .

The calculated weights using the traditional method are more balanced, however: no alternative or attribute scored 0.00 , which contributed for lowering the difference of the fi- 
Table 4. Evaluation matrix with respect to the criterion "Security management".

\begin{tabular}{|l|c|c|c|c|c|}
\hline & Suppl.1 & Suppl.2 & Suppl.3 & Suppl.4 & Suppl.5 \\
\hline Suppl.1 & $(1,1,1)$ & $(1,1,1)$ & $\left(\frac{2}{3}, 1, \frac{3}{2}\right)$ & $\left(\frac{2}{5}, \frac{1}{2}, \frac{2}{3}\right)$ & $(1,1,1)$ \\
\hline Suppl.2 & & $(1,1,1)$ & $\left(\frac{2}{3}, 1, \frac{3}{2}\right)$ & $\left(\frac{2}{5}, \frac{1}{2}, \frac{2}{3}\right)$ & $(1,1,1)$ \\
\hline Suppl.3 & & $(1,1,1)$ & $\left(\frac{2}{7}, \frac{1}{3}, \frac{2}{5}\right)$ & $\left(\frac{2}{3}, 1, \frac{3}{2}\right)$ \\
\hline Suppl.4 & & & $(1,1,1)$ & $(1,1,1)$ \\
\hline Suppl.5 & & & & & $(1,1,1)$ \\
\hline
\end{tabular}

Source: The authors own.

Table 5. Evaluation matrix with respect to the criterion "Cost".

\begin{tabular}{|l|c|c|c|c|c|}
\hline & Suppl.1 & Suppl.2 & Suppl.3 & Suppl.4 & Suppl.5 \\
\hline Suppl.1 & $(1,1,1)$ & $\left(\frac{3}{2}, 2, \frac{5}{2}\right)$ & $\left(\frac{3}{2}, 2, \frac{5}{2}\right)$ & $\left(\frac{5}{2}, 3, \frac{7}{2}\right)$ & $\left(\frac{5}{2}, 3, \frac{7}{2}\right)$ \\
\hline Suppl.2 & & $(1,1,1)$ & $\left(\frac{2}{3}, 1, \frac{3}{2}\right)$ & $\left(\frac{3}{2}, 2, \frac{5}{2}\right)$ & $\left(\frac{5}{2}, 3, \frac{7}{2}\right)$ \\
\hline Suppl.3 & & $(1,1,1)$ & $\left(\frac{5}{2}, 3, \frac{7}{2}\right)$ & $\left(\frac{5}{2}, 3, \frac{7}{2}\right)$ \\
\hline Suppl.4 & & & $(1,1,1)$ & $\left(\frac{2}{3}, 1, \frac{3}{2}\right)$ \\
\hline Suppl.5 & & & & & $(1,1,1)$ \\
\hline
\end{tabular}

Source: The authors own.

Table 6. Overall scores in the fuzzy AHP method.

\begin{tabular}{|c|c|c|c|c|c|c|c|c|c|}
\hline & TEC & FIN & REL & OPE & SEC & INF & HIS & $\cos$ & Priority weight \\
\hline Weight & 0.00 & 0.00 & 0.00 & 0.00 & 0.59 & 0.00 & 0.00 & 0.41 & \\
\hline \multicolumn{10}{|c|}{ Alternatives } \\
\hline Supplier 1 & 0.30 & 0.03 & 0.20 & 0.55 & 0.00 & 0.48 & 0.33 & 0.46 & 0.19 \\
\hline Supplier 2 & 0.00 & 0.36 & 0.20 & 0.08 & 0.00 & 0.00 & 0.22 & 0.24 & 0.10 \\
\hline Supplier 3 & 0.00 & 0.00 & 0.20 & 0.16 & 0.09 & 0.00 & 0.02 & 0.30 & 0.17 \\
\hline Supplier 4 & 0.31 & 0.14 & 0.20 & 0.16 & 0.91 & 0.48 & 0.29 & 0.00 & 0.54 \\
\hline Supplier 5 & 0.38 & 0.47 & 0.20 & 0.06 & 0.00 & 0.04 & 0.14 & 0.00 & 0.00 \\
\hline
\end{tabular}


Table 7. Overall scores in the AHP method.

\begin{tabular}{|c|l|l|l|l|l|l|l|l|l|l|l|}
\hline & TEC & FIN & REL & OPE & SEC & INF & HIS & COS & Priority weight \\
\hline Weight & 0.08 & 0.01 & 0.06 & 0.05 & 0.43 & 0.06 & 0.06 & 0.26 & \\
\hline \multicolumn{10}{|c|}{ Alternatives } \\
\hline Supplier 1 & 0.29 & 0.15 & 0.29 & 0.34 & 0.10 & 0.32 & 0.40 & 0.52 & 0.28 \\
Supplier 2 & 0.07 & 0.24 & 0.15 & 0.16 & 0.10 & 0.10 & 0.21 & 0.23 & 0.14 \\
Supplier 3 & 0.03 & 0.05 & 0.10 & 0.08 & 0.14 & 0.05 & 0.07 & 0.16 & 0.12 \\
Supplier 4 & 0.23 & 0.16 & 0.29 & 0.23 & 0.46 & 0.32 & 0.18 & 0.05 & 0.29 \\
Supplier 5 & 0.38 & 0.41 & 0.18 & 0.18 & 0.21 & 0.20 & 0.14 & 0.03 & 0.17 \\
\hline
\end{tabular}

Source: The authors own.

nal priority between the first ranked supplier and the second one, from $0.35(0.54-0.19)$ to $0.01(0.29-0.28)$.

It should be noted that both first and second ranked suppliers in the applied methods have been actually selected by the company for providing the services. Besides, the model structure and outcomes were adopted by the specialists for defending the procurement process before the company's board of directors, making it a regular procedure for processes involving more than $\mathrm{R} \$ 1$ million ( US\$300,000).

\section{CONCLUSIONS}

A decision support model can help organizations to select more appropriate suppliers according to the specific objectives of their supply chain, breaking the complex problem in several levels of assessment. Also, it can consider the viewpoints of multi-agents and provide an easy-to-explain structure that can be used in similar processes in the future.

In this study, eight attributes were defined to evaluate five potential suppliers for providing rail track maintenance services. The fuzzy AHP approach has been adopted and the results were compared with AHP, applying a conversion scale between methods. Fuzzy numbers handle uncertainty in terms of judgments whilst input linguistic judgments are triangular probabilistic distributions. The extent analysis detaches the attributes that truly influence the problem: in this application, two out of eight criteria - "cost" and "security management" - scored weights different from 0 , a result quite aligned to the major concern of the company in recent years.

The proposed model was applied to only one selection process, but it can be easily extended to other processes in other areas of the industry. The model can be extended by creating an intermediate level of sub attributes between the attributes and alternatives composed by more specific measurements units. This could not be achieved in this study, as the pair-wise comparisons would require too much judging time from the specialists - it would be necessary to con- struct 36 more matrixes. This can be solved by combining the fuzzy AHP method with other MDCM, such as TOPSIS. Mathematical programming can be applied for cases that supplier's capacity constraints must be taken into account.

The judgment matrixes were constructed from the data collected in printed forms and calculations performed in Octave language (2016). Also, the model could be integrated to the company's ERP through an online application, so more transactional data could be applied and faster feedbacks received by the decision-makers. The defined problem was to select the best supplier; however, the same methodology can be developed for reviewing the firms already providing services for the company.

\section{REFERENCES}

Abdullah, L., and Najib, L. (2014). A new type-2 fuzzy set of linguistic variables for the fuzzy analytic hierarchy process. Expert Systems with Applications, Vol. 41, No. 7, pp. 3297-3305.

Ayhan, M. B. (2013). A fuzzy AHP approach for supplier selection problem: A case study in a Gear motor company. International Journal of Managing Value and Supply Chains, Vol. 4, No. 3, pp. 11-23.

Boyett, I., Robinson, P., Brown, A., and Finlay, D. (1996). Supplier-purchaser relationships within a quasi-market: the case of British Rail and British Steel Track Products. European Journal of Purchasing and Supply Management, Vol. 2, No. 2, pp. 145-151.

Bruno, G., Esposito, E., Genovese, A., and Passaro, R. (2012). AHP-based approaches for supplier evaluation: Problems and perspectives. Journal of Purchasing and Supply Management, Vol. 18, No. 3, pp. 159-172.

Catak, F. O., Karabas, S., and Yildirim, S. (2012). Fuzzy analytic hierarchy based DBMS selection in turkish national identity card management project. International Journal of Information Sciences and Techniques, Vol. 2, Np. 4, pp. 29-38.

Cebeci, U. (2009). Fuzzy AHP-based decision support system for selecting ERP systems in textile industry by using ba- 
lanced scorecard. Expert Systems with Applications, Vol. 36, No. 5, pp. 8900-8909.

Cevik Onar, S., Oztaysi, B., and Kahraman, C. (2014). Strategic decision selection using hesitant fuzzy TOPSIS and interval type-2 fuzzy AHP: a case study. International Journal of Computational Intelligence Systems, Vol. 7, No. 5, pp. 1002-1021.

Chai, J., Liu, J. N., and Ngai, E. W. (2013). Application of decision-making techniques in supplier selection: A systematic review of literature. Expert Systems with Applications, Vol. 40, No. 10, pp. 3872-3885.

Chamodrakas, I., Batis, D., and Martakos, D. (2010). Supplier selection in electronic marketplaces using satisficing and fuzzy AHP. Expert Systems with Applications, Vol. 37, No. 1, pp. 490-498.

Chan, F. T., and Kumar, N. (2007). Global supplier development considering risk factors using fuzzy extended AHP-based approach. Omega, Vol. 35, No. 4, pp. 417-431.

Chang, D. Y. (1996). Applications of the extent analysis method on fuzzy AHP. European Journal of Operational Research, Vol. 95, No. 3, pp. 649-655.

De Boer, L., Labro, E., and Morlacchi, P. (2001). A review of methods supporting supplier selection. European Journal of Purchasing and Supply Management, Vol. 7, No. 2, pp. 75-89.

Dulmin, R., and Mininno, V. (2003). Supplier selection using a multi-criteria decision aid method. Journal of Purchasing and Supply Management, Vol. 9, No. 4, pp. 177-187.

Ho, W., Xu, X., and Dey, P. K. (2010). Multi-criteria decision making approaches for supplier evaluation and selection: $A$ literature review. European Journal of Operational Research, Vol. 202, No. 1, pp. 16-24.

Kahraman, C., Cebeci, U., and Ruan, D. (2004). Multi-attribute comparison of catering service companies using fuzzy AHP: The case of Turkey. International Journal of Production Economics, Vol. 87, No. 2, pp. 171-184.

Kahraman, C., Cebeci, U., and Ulukan, Z. (2003). Multi-criteria supplier selection using fuzzy AHP. Logistics Information Management, Vol. 16, No. 6, pp. 382-394.
Kilincci, O., and Onal, S. A. (2011). Fuzzy AHP approach for supplier selection in a washing machine company. Expert systems with Applications, Vol. 38, No. 8, pp. 9656-9664.

Kwong, C. K., and Bai, H. (2003). Determining the importance weights for the customer requirements in QFD using a fuzzy AHP with an extent analysis approach. IIE Transactions, Vol. 35, No. 7, pp. 619-626.

Lima Junior, F. R., Osiro, L., and Carpinetti, L. C. R. (2013). Métodos de decisão multicritério para seleção de fornecedores: um panorama do estado da arte. Gestão e Produção, Vol. 20, No. 4, pp. 781-801.

Memon, M. S., Lee, Y. H., and Mari, S. I. (2015). Group multi-criteria supplier selection using combined grey systems theory and uncertainty theory. Expert Systems with Applications, Vol. 42, No. 21, pp. 7951-7959.

Octave (2016) A high-level interpreted language. Available at: http://www.gnu.org/software/octave/ on 23-april-2016

Saaty, R. W. (1987). The analytic hierarchy process - what it is and how it is used. Mathematical Modelling, Vol. 9, No. 3-5, pp. 161-176.

Uçal Sarý, I., Öztayşi, B., and Kahraman, C. (2013). Fuzzy Analytic Hierarchy Process Using Type-2 Fuzzy Sets: An Application to Warehouse Location Selection. Multicriteria Decision Aid and Artificial Intelligence, pp. 285-308.

Villanueva-Ponce, R., Avelar-Sosa, L., Alvarado-Iniesta, A., and Cruz-Sánchez, V. G. (2015). The green supplier selection as a key element in a supply chain: A review of cases studies. Dyna, Vol. 82, No. 194, pp. 36-45.

Wang, W., Liu, X., and Qin, Y. (2012). Multi-attribute group decision making models under interval type-2 fuzzy environment. Knowledge-Based Systems, Vol. 30, pp. 121-128.

Yadav, V., and Sharma, M. K. (2015). Multi-criteria decision making for supplier selection using fuzzy AHP approach. Benchmarking: An International Journal, Vol. 22, No. 6, pp. 11581174.

Zadeh, L. A. (1965). Fuzzy sets. Information and Control, Vol. 8, No. 3, pp. 338-353. 